\title{
Clinical Profile of Patients with Disseminated Tuberculosis (DTB) in Human Immune Deficiency Virus (HIV) Infection
}

\author{
Rajneesh Thakur', Mohammed Schezan Iqbal',*, Farah Schezan ${ }^{3}$
}

\begin{abstract}
Background: We evaluated the clinical profile of HIV positive patients freshly diagnosed with Disseminated Tuberculosis (DTB) and assessed their response to Anti-tuberculosis treatment (ATT). Aim: To describe various clinical, radiological and pathological parameters encountered in patients of Disseminated Tuberculosis having an HIV co-infection and assessing the response to standard ATT. Settings and Design: This study is a descriptive study. Materials and Methods: We conducted a study on 54 patients of disseminated TB with HIV coinfection who were already on Anti-retroviral therapy. Assessment was focused on mode of diagnosis and distribution of organ involvement. Four months of HRZE and two months of HRE were prescribed as the standard ATT. Effect of this treatment was observed on change in weight, $\mathrm{CD}_{4}$ counts and HIV RNA viral loads. Statistical analysis used: Wilcoxon Sign Rank Test for assessing response to ATT. Results: This study included 54 patients. The lymphatic system was the most commonly involved organ system $(64.81 \%)$ and other organs involved were the liver $(55.56 \%)$, the lungs $(46.3 \%)$, the pleurae $(12.96 \%)$, the meninges $(5.54 \%)$ and the bone marrow $(3.71 \%)$. Median weight at baseline was $53 \mathrm{~kg}(I \mathrm{QR}, 49-58)$ and after six months of standard ATT was $62 \mathrm{~kg}(I \mathrm{QR}, 58-67)(p<0.001)$. Median $\mathrm{CD}_{4+}$ count at baseline was 107.5 cells $/ \mathrm{mm}^{3}$ (IQR, 51.5-150.75) and after six months of standard $A T^{4+}$ was 246 cells $/ \mathrm{mm}^{3}$ (IQR, 184-335.75) $(p<0.001)$. Median HIV RNA viral load at baseline was 2,83,575 copies/mL (IOR, 1,78,376.25 - 3,83,370) and after six months of standard ATT was $19,916.5$ copies/mL $(14,376.25-28,622.5)(p<0.001)$. Conclusion: DTB in HIV positive patients has a variety of clinical manifestations which should be incorporated in the clinical decision making and change in weight, $\mathrm{CD}_{4+}$ count and HIV RNA viral load is a reliable indicator of therapeutic response in such cases.

Key words: Disseminated TB, HIV, Clinical Profile, ATT, Plasma HIV RNA viral load.

Key Messages: Anti-Tubercular Therapy (ATT) is instrumental in improving clinical and serological parameters in patients of Disseminated TB having an HIV co-infection.
\end{abstract}

\section{Rajneesh Thakur ${ }^{1}$, Mohammed Schezan |qbal ${ }^{2, *}$, Farah Schezan ${ }^{3}$ 'Department of Internal Medicine, AFMC, Pune, Maharashtra, INDIA. 'Department of Orthopaedics, AFMC, Pune, Maharashtra, INDIA. ${ }^{3}$ Bachelor of Dental Surgery, Terna Dental College, Navi Mumbai, Maharashtra, INDIA. \\ Correspondence \\ Dr. Mohammed Schezan Iqbal, Department of Orthopaedics, AFMC, Southern Command, Near Racecourse, Pune-411040, Maharashtra, INDIA. Mobile no: +91020 26723026 \\ Email: dr.schezan@outlook.com \\ History \\ - Submission Date: 15-08-2019; \\ - Revised Date: 21-09-2019; \\ - Accepted Date: 19-11-2019;}

DOI : 10.5530/ijmedph.2019.4.28

Article Available online

http://www.ijmedph.org/v9/i4

\section{Copyright}

(C) 2019 Phcog.Net. This is an openaccess article distributed under the terms of the Creative Commons Attribution 4.0 International license.

\section{INTRODUCTION}

Tuberculosis (TB) poses a significant threat to global health even today, causing the second highest mortality rates from an infectious disease worldwide, after Human Immunodeficiency Virus/Acquired Immune-Deficiency Syndrome (HIV/AIDS). TB and HIV are overlapping epidemics and continue to be a major public health challenge. The World Health Organization (WHO) Global Status Report 2016, reports 10.4 million new cases of TB in 2015 of whom $11 \%$ were HIV-infected. ${ }^{1}$ This is an increase in the number of new TB cases from 9.2 million seen in 2014.

As $\mathrm{HIV}$ infection progresses, $\mathrm{CD}_{4}$ lymphocytes decline in number and function, making the immune system less able to prevent the growth and local spread of $M$. tuberculosis. ${ }^{2}$ The risk of TB infection progressing to active TB is estimated to be eight percent per year in an HIV positive person versus a life time risk of ten percent in an immune competent person. ${ }^{3}$ This is important in India where estimates are that more than half the adults harbour M. tuberculosis

infection. ${ }^{4}$ With advancing disease, atypical forms of TB become common like tubercular lymphadenitis, smear negative pulmonary tuberculosis and disseminated TB.

Disseminated Tuberculosis (DTB) is defined as a tubercular process involving two or more non-contiguous organs or involvement of bone or blood. DTB may occur during primary infection or reactivation of latent TB. ${ }^{5}$ An interesting point to be made about DTB is the non-specificity of its symptoms; which, in the absence of lung involvement, can lead to an adverse delay in diagnosis.

This study was meant to study the clinical profile of patients with DTB with an HIV positive status, as very few epidemiological studies have been performed to determine the clinical outline of disseminated tuberculosis in HIV positive individuals till date.

\section{MATERIALS AND METHODS}

The present study was conducted over a nine-month period from $1^{\text {st }}$ January 2018 to $30^{\text {th }}$ September 2018

Cite this article : Thakur R, Iqbal MS, Farah S. Clinical Profile of Patients with Disseminated Tuberculosis (DTB) in Human Immune Deficiency Virus (HIV) Infection. Int J Med Public Health. 2019;9(4):131-6. 
in a tertiary care hospital of western India. Ethical clearance was obtained from the Institutional Ethics Committee.

Case Definitions: Cases have been defined based on definitions provided in WHO- Definitions and reporting framework for tuberculosis - 2013 Revision. ${ }^{5}$

Presumptive TB refers to a patient who presents with symptoms or signs suggestive of TB (previously known as a TB suspect).

A bacteriologically confirmed TB case is one from whom a biological specimen is positive by smear microscopy, culture or WRD (such as expert MTB/RIF).

A clinically diagnosed TB case is one who does not fulfil the criteria for bacteriological confirmation but has been diagnosed with active TB by a clinician or other medical practitioner who has decided to give the patient a full course of TB treatment.

Bacteriologically confirmed or clinically diagnosed cases of TB are further classified as:

\section{Classification based on anatomical site of disease}

Pulmonary Tuberculosis (PTB) refers to any bacteriologically confirmed or clinically diagnosed case of TB involving the lung parenchyma or the tracheobronchial tree.

Military TB is classified as PTB because there are lesions in the lungs.

Disseminated Tuberculosis is a disease process involving two or more non-contiguous organs or involvement of bone or blood due to widespread blood borne dissemination of TB bacilli.

Extrapulmonary Tuberculosis (EPTB) refers to any bacteriologically confirmed or clinically diagnosed case of TB involving organs other than the lungs, e.g. pleura, lymph nodes, abdomen, genitourinary tract, skin, joints and bones, meninges.

\section{Classification based on history of previous TB treatment}

New patients have never been treated for TB or have taken anti-TB drugs for less than 1 month.

Previously treated patients have received 1 month or more of anti-TB drugs in the past.

\section{Classification based on HIV status}

HIV-positive TB patient refers to any bacteriologically confirmed or clinically diagnosed case of TB who has a positive result from HIV testing conducted at the time of TB diagnosis or other documented evidence of enrolment in HIV care, such as enrolment in the pre-ART (Anti-retroviral therapy) register or in the ART register once ART has been started.

HIV-negative TB patient refers to any bacteriologically confirmed or clinically diagnosed case of TB who has a negative result from HIV testing conducted at the time of TB diagnosis. Any HIV-negative TB patient subsequently found to be HIV-positive should be reclassified accordingly.

HIV status unknown TB patient refers to any bacteriologically confirmed or clinically diagnosed case of TB who has no result of HIV testing and no other documented evidence of enrolment in HIV care.

\section{Inclusion criteria}

i) All patients aged 18 years and above, who were known to be HIV positive and were freshly diagnosed to have disseminated tuberculosis based on clinical/radiological/microbiological evidence.

ii) Patients who could be followed up either via telephone or personally and showed a good compliance to pre-existing Anti-retroviral therapy.

\section{Exclusion criteria}

i) All patients who were known to be HIV positive and already diagnosed cases of TB (Pulmonary, extrapulmonary, disseminated) and already on ATT.

ii) All patients who could not be followed up either due to long distance or were of a doubtful compliance, based on defaults in anti-retroviral therapy.

All patients who satisfied the above criteria were counselled and a written informed consent was obtained before enlisting them in the study. All patients were assessed clinically for any signs and symptoms. Baseline parameters and baseline $\mathrm{CD}_{4+}$ counts and HIV RNA viral loads were noted. All patients were already on an existing supervised, standard Anti Retro Viral Therapy (ART) regimen (Tenofovir + Lamivudine + Efavirenz) which is available as a fixed dose combination in one tablet. All patients were prescribed a standard Anti-Tubercular Therapy (ATT) of two months HRZE and four months of HRE (Daily regime). Response was assessed at the end of study for any changes in each patient based on clinical grounds in terms of remission of symptoms and increase in weight, immunological status using $\mathrm{CD}_{4+}$ counts, any changes in the HIV viral loads and during the study for any adverse drug reactions to the ATT regimen.

\section{Statistical analysis}

The Data was recorded on a predesigned data sheet and all entries were double checked for any possible feeding error. Statistical analysis was performed using SPSS very 21 using appropriate statistical tests. A confidence interval of $95 \%$ and $p$ value of less than 0.05 were considered to be statistically significant.

\section{RESULTS}

During the study period, a total of 54 patients with disseminated TB and HIV co-infection were included. The demographic profile of the study population is represented in Table 1.

The median age at presentation in HIV patients was 36 years (IQR, 31.25 - 40.75) with the maximum number in the third decade. The median BMI of the study population before institution of Anti-Tubercular Therapy (ATT) was $19.20 \mathrm{~kg} / \mathrm{m}^{2}$ (IQR, 16.79 - 20.08). The median CD4+ count of the study sample before start of ATT was found to be 107.5 cells/ $\mathrm{m}^{3}$ (IQR, 51.5 - 150.75).

The median time interval between diagnosis of HIV infection and TB diagnosis was 37 days (IQR, 16-113).

Of the 54 patients, 2 were found to be AFB positive on sputum examination, 14 yielded positive results for Mycobacterium tuberculosis on tissue examination and 50 had significant changes on radiological evaluation, including CT scan and ultrasound. This has been demonstrated in Table 2 .

In our study, we found that involvement of the lymphatic system was the commonest, with 35 out of 54 patients (64.81\%) being diagnosed to have DTB of the lymphatic system alone or in conjunction with other organ systems. The other commonly involved organ systems included the liver (55.56\%), the lungs (46.3\%), the pleurae (12.96\%), the meninges (5.54\%) and the bone marrow (3.71\%). These results are depicted in Figure 1.

Weight change after standard six months of ATT was measured and Wilcoxon Sign rank test was applied for significance. There was a statistically significant weight gain after completion of ATT in all age groups ( $p$ value $<0.001)$. These have been summarized in Table 3 and Figure 2.

The immunological profile of the sample was assessed by examining the patients' $\mathrm{CD}_{4+}$ counts at the time of diagnosis and after completion of ATT. The median values of the $\mathrm{CD}_{4+}$ profile have been outlined in 


\begin{tabular}{|c|c|c|c|c|c|c|}
\hline $\begin{array}{l}\text { Age Group } \\
\text { (Years) }\end{array}$ & No (n) & $\begin{array}{c}\text { Weight at } \\
\text { baseline (kg) }\end{array}$ & $\begin{array}{c}\text { Height at } \\
\text { baseline }(\mathrm{cm})\end{array}$ & $\begin{array}{l}\text { BMI before at baseline } \\
\qquad\left(\mathrm{kg} / \mathrm{m}^{2}\right)\end{array}$ & $\begin{array}{c}\mathrm{CD}_{4+} \text { count at } \\
\text { baseline (cells / } \\
\mathrm{mm}^{3} \text { ) }\end{array}$ & $\begin{array}{l}\text { HIV RNA viral load at } \\
\text { baseline (copies } / \mathrm{mL} \text { ) }\end{array}$ \\
\hline $25-34$ & 25 & $55(49-58)$ & $172(168-174)$ & $19.16(16.49-20.09)$ & $94(56-130)$ & $\begin{array}{c}3,30,541 \\
(1,89,924-5,02,178)\end{array}$ \\
\hline $35-44$ & 21 & $55(51-59)$ & $170(165-174)$ & $18.96(17.69-21.56)$ & $122(91-157)$ & $\begin{array}{c}2,25,316(1,41,824- \\
3,00,105)\end{array}$ \\
\hline$>45$ & 8 & $47(43-53)$ & $165(151-167)$ & $19.43(15.67-19.77)$ & $115(50-173)$ & $\begin{array}{c}3,11,526.5(2,38,689.25- \\
3,58,537)\end{array}$ \\
\hline TOTAL & 54 & $53(49-58)$ & $170(165-174)$ & $19.20(16.79-20.08)$ & $\begin{array}{c}107.5(51.5- \\
150.75)\end{array}$ & $\begin{array}{c}2,83,575 \\
(1,78,376.25- \\
3,83,370)\end{array}$ \\
\hline
\end{tabular}

${ }^{*}$ All values are given as median (Interquartile range).

\begin{tabular}{|c|c|c|c|c|c|c|c|c|c|}
\hline \multirow[t]{2}{*}{ Age } & \multirow[t]{2}{*}{ No. $(n=54)$} & \multicolumn{4}{|c|}{ Clinical features } & \multicolumn{2}{|c|}{ Imaging } & \multicolumn{2}{|c|}{ AFB positivity } \\
\hline & & Fever & Cough & LNPathy & Weight loss & $\begin{array}{l}\text { CE-CT Chest } \\
\text { and Abdomen }\end{array}$ & USG & Sputum & Tissue \\
\hline $25-34$ & 25 & $21(84)$ & $4(16)$ & $15(60)$ & $13(52)$ & $11(44)$ & $17(68)$ & $2(8)$ & $6(24)$ \\
\hline $35-44$ & 21 & $14(66.7)$ & $6(28.6)$ & $9(42.8)$ & $11(52.4)$ & $9(42.8)$ & $9(42.8)$ & $0(0)$ & $5(23.8)$ \\
\hline$>45$ & 8 & $7(87.5)$ & $5(62)$ & $5(62)$ & $4(50)$ & $4(50)$ & $5(62)$ & $0(0)$ & $3(37.5)$ \\
\hline TOTAL & 54 & $42(77.7)$ & $15(27.7)$ & $29(53.7)$ & $28(51.8)$ & $24(44.5)$ & $41(75.9)$ & $2(3.7)$ & $14(25.9)$ \\
\hline
\end{tabular}

${ }^{*}$ Values are given as No. (\%).

\begin{tabular}{ccccc}
\multicolumn{4}{l}{ Table 3: Weight change after ATT $(\mathbf{n = 5 4 )}$ * } & $p$ value \\
Age & $\begin{array}{c}\text { No. } \\
(n=54)\end{array}$ & \multicolumn{2}{l}{ Weight change } & \\
& & $\begin{array}{c}\text { Weight before } \\
\text { ATT }(\mathrm{kg})\end{array}$ & $\begin{array}{c}\text { Weight after } \\
\text { ATT }(\mathrm{kg})\end{array}$ & \\
\hline $25-34$ & 25 & $55(49-58)$ & $63(60-70)$ & $<0.001$ \\
$35-44$ & 21 & $55(51-59)$ & $65(58-66)$ & $<0.001$ \\
$>45$ & 8 & $47(43-53)$ & $55.5(46.75-62)$ & 0.043 \\
TOTAL & 54 & $53(49-58)$ & $62(58-67)$ & $<0.001$
\end{tabular}

*All values are given as median (Interquartile range).

Table 4 and Figure 3, showing difference in median $\mathrm{CD}_{4+}$ counts of the sample before and after completion of ATT. There was a statistically significant difference in these values which was assessed by Wilcoxon Sign Rank test.

The HIV RNA viral load of the study population was assessed by examining the patients' HIV RNA viral loads at the time of diagnosis and after completion of ATT. The median values of the HIV viral loads (copies/ $\mathrm{mL}$ ) have been outlined in Table 5 and Figure 4 shows the difference in the median HIV viral load of the study sample before and after completion of ATT. There was a statistically significant difference between the HIV RNA viral loads before and after ATT, which was calculated using the Wilcoxon Sign Rank test ( $p$ value $<0.001$ ).

We also studied the adverse events related to ATT and found out that only two patients of our study sample (3.7\%) developed adverse reactions to ATT. The diagnosis of hepatoxicity in our study was based on

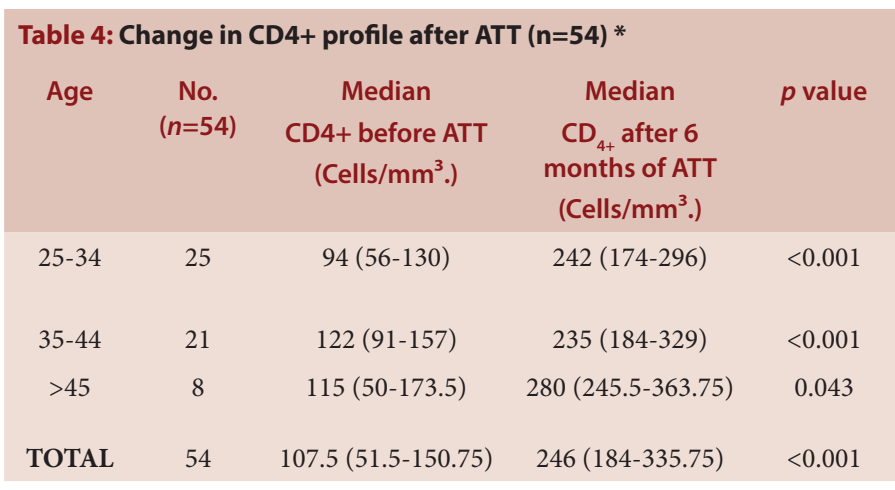

${ }^{\star}$ Values are given as median (Interquartile range)

exclusion of other possible causes, the temporal profile of liver injury and response to temporary cessation of therapy. Similarly, a diagnosis of neuropathy was based after excluding other possible etiological factors. One patient developed transient hepatitis with elevated liver enzymes (SGOT, SGPT) with no clinical jaundice, which subsided after temporary cessation of ATT. One patient developed progressive peripheral neuropathy, which was attributed to Isoniazid in the ATT regimen and the patient was started on Tab Pyridoxine $100 \mathrm{mg}$ per day and his symptoms at the end of our study showed marked improvement.

\section{DISCUSSION}

In this study, the median age at presentation in HIV patients was 37 years with the maximum number in the third decade. Maheshwari et al. ${ }^{4}$ have recorded the highest incidence of HIV patients in the third decade. Various other Indian and African studies have also shown similar results. ${ }^{6,7}$ 


\begin{tabular}{|c|c|c|c|c|}
\hline \multirow[t]{2}{*}{ Age } & \multirow[t]{2}{*}{$\begin{array}{l}\text { No. } \\
(n=54)\end{array}$} & $\begin{array}{l}\text { Median } \\
\text { HIV RNA viral } \\
\text { load before ATT }\end{array}$ & $\begin{array}{c}\text { Median } \\
\text { HIV RNA viral load } \\
\text { after } 6 \text { months of ATT }\end{array}$ & \multirow[t]{2}{*}{$p$ value } \\
\hline & & (Copies/mL) & (Copies/mL) & \\
\hline $25-34$ & 25 & $\begin{array}{c}3,30,541 \\
(1,89,924- \\
5,02,178)\end{array}$ & $\begin{array}{c}24,810(18,620- \\
37,819)\end{array}$ & $<0.001$ \\
\hline $35-44$ & 21 & $\begin{array}{c}2,25,316 \\
(1,41,824- \\
3,00,105)\end{array}$ & $\begin{array}{c}17,825(14,037- \\
26,728)\end{array}$ & $<0.001$ \\
\hline$>45$ & 8 & $\begin{array}{c}3,11,526.5 \\
(2,38,689.25- \\
3,58,537)\end{array}$ & $\begin{array}{c}16,772.5(12,800.25- \\
19,874.25)\end{array}$ & 0.043 \\
\hline TOTAL & 54 & $\begin{array}{c}2,83,575 \\
(1,78,376.25- \\
3,83,370)\end{array}$ & $\begin{array}{c}19,916.5(14,376.25- \\
28,622.5)\end{array}$ & $<0.001$ \\
\hline
\end{tabular}

${ }^{*}$ Values are given as median (Interquartile range)

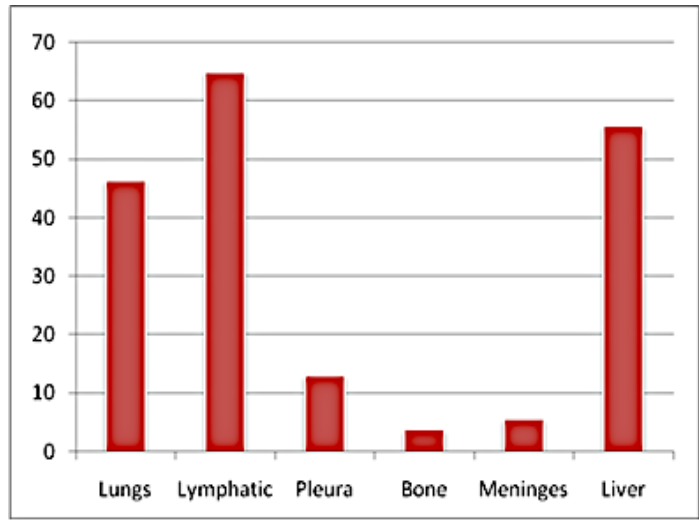

Figure 1: Organ involvement in DTB.*

*All values are in \%

We studied the clinical profile of these patients and found that the commonest symptoms in descending order were fever, lymphadenopathy, weight loss and cough with expectoration. Fever has also been shown to be the commonest manifestation of DTB. ${ }^{8}$ Therefore, TB remains an important cause in any HIV positive patient presenting with fever.

Organ systems involved in the tubercular disease process were individually evaluated by clinical, histological and radiological methods and the lymphatic system was the most commonly involved, with 35 out of 54 patients (64.81\%) being diagnosed to have DTB of the lymphatic system alone or in conjunction with other organ systems. In another study done by this author, the incidence of lymph node involvement was $47.03 \%{ }^{9}$ Lymphadenopathy has been a common examination finding in various other studies as well. ${ }^{10,11}$ A clinician should keep a high level of suspicion for DTB in an HIV positive individual if presenting with lymphadenopathy, hepatomegaly, cough or signs of meningitis or bone and joint pains. In severely immune-suppressed patients with pulmonary tuberculosis, chest radiographs may be normal $10 \%-40 \%$ of the time; however, a variety of abnormalities including effusion, lymphadenopathy and nodular opacities are also seen..$^{12}$ In our study we found noteworthy radiological findings in 50 patients (92.6\%), which included consolidation, pleural effusion, parenchymal opacities and hilar lymphadenopathy on CECT

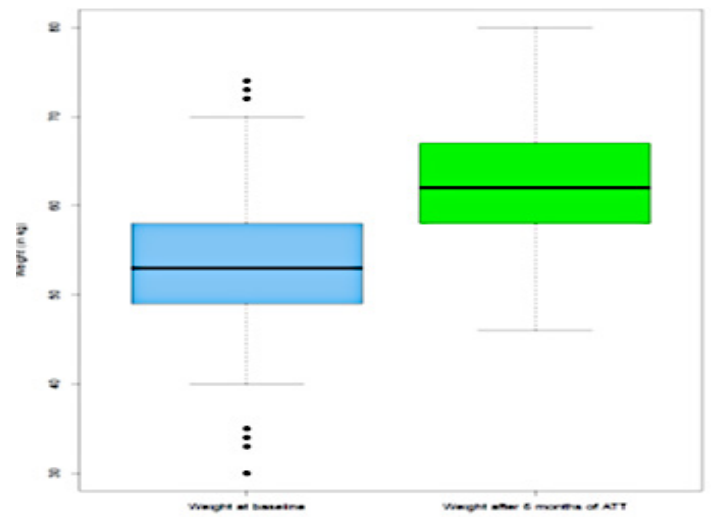

Figure 2: Median weight before and after ATT.

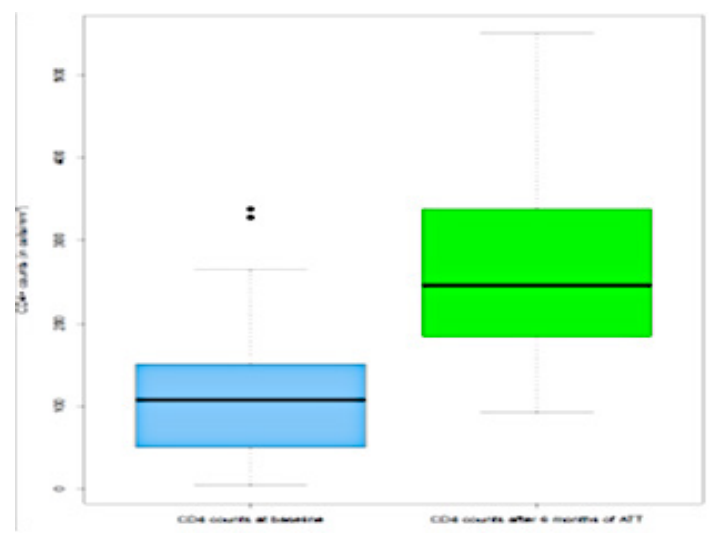

Figure 3: Median CD4+ counts before and after ATT.

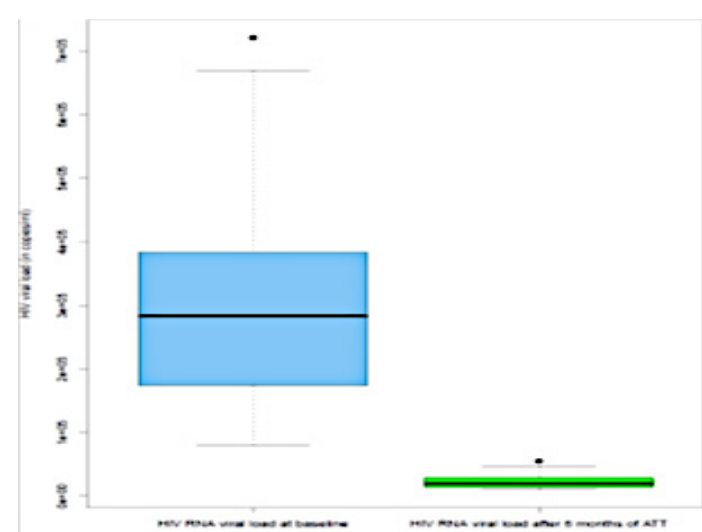

Figure 4: Median HIV RNA viral load before and after ATT.

Chest and hepatosplenomegaly, retro peritoneal lymphadenopathy with ascites on abdominal ultrasonography.

An important finding of our study is that only 2 patients out of 54 (3.70\%) were positive for Acid Fast Bacilli (AFB) on sputum examination while 52 remained sputum negative. This has a bearing on the diagnosis of DTB in a way that a majority of DTB and co-existing HIV positive patients would not provide positive sputum for AFB on Z-N staining, which is extensively used all across India. Similar results were shown by this author in another study, in which the incidence of smear negative TB was much more common than smear positive TB. ${ }^{9}$

Histopathological examination of suspected tissues in the form of fine needle aspiration cytology (FNAC), biopsies and aspirates yielded a posi- 
tive bacteriological diagnosis in 14 patients (25.93\%), in whom a clinical or radiological diagnosis was in doubt. However, with advancing immune suppression, atypical findings including less well-formed granulomas maybe seen. ${ }^{13}$ Excisional biopsy has the highest sensitivity, whereas FNAC is less invasive and may be useful with a reduced sensitivity. ${ }^{14}$ The diagnostic accuracy could be further increased by combining the results of the biopsy histology, Polymerase Chain Reaction (PCR) and cultures. Likewise, both sensitivities (82.4\%-100\%) and specificities (94\%-100\%) were increased when fine needle aspiration (FNA) cytology and PCR were combined in the diagnosis of TB lymphadenitis. ${ }^{14,15}$

Immunological profile of the patients was evaluated based on $\mathrm{CD}_{4+}$ counts, which is a reliable indicator of the immune status of an individual. A meta-analysis estimated a 1.43 -fold (95\% credible interval: 1.161.88) increase in TB incidence per 100 cells per $\mathrm{mm}^{3}$ decrease in $\mathrm{CD}_{4}$ cell count. ${ }^{16}$ In our study, the $\mathrm{CD}_{4}$ counts of the HIV positive patients ranged between 4 and 338 cells $/ \mathrm{m}^{3}$ (median 110 cells $/ \mathrm{m}^{3}$ ); $92.6 \%$ of the patients had $\mathrm{CD}_{4}$ counts of $<200$ cells $/ \mathrm{m}^{3}$ and $25.9 \%$ had a $\mathrm{CD}_{4}$ count of $<50$ cells $/ \mathrm{m}^{3}$, indicating that a significant number of patients had profound immunosuppression at the time of investigation for symptomatic HIV/ TB disease. In a South African study, it was seen that $61.2 \%$ had CD4 cell counts $<200$ cells $/ \mu \mathrm{L}, 82.7 \%$ had counts $<350$ cells $/ \mu \mathrm{L} .{ }^{17}$

Patients were then put on a standard ATT regimen and $\mathrm{CD}_{4+}$ levels were again checked at end of ATT. This showed a dramatic increase in all patients, with a median rise of 148 cells $/ \mathrm{m}^{3}$. With a CI of $95 \%$ and $\mathrm{p}$ value of $<0.001$, this is a highly significant difference and supports the fact that a complete and early ATT institution can increase the $\mathrm{CD}_{4+}$ count, thereby reducing the harmful effect of immunosuppression, as it is known that frequency and severity of DTB increases as $\mathrm{CD}_{4+}$ counts fall. ${ }^{18}$ In an African study it was seen that $\mathrm{CD}_{4}$ cell levels increased significantly during the course of ATT in both HIV+ and HIV- TB-patients, but did not reach the levels in healthy subjects. ${ }^{19}$ In the same study it was shown that the continuous increase of $\mathrm{CD}_{4}$ cell counts during treatment for TB strongly suggests that $\mathrm{TB}$ per se contributes to subnormal $\mathrm{CD}_{4}$ cell levels in peripheral blood. Another study compared the improvement in $\mathrm{CD}_{4}$ count following $\mathrm{ATT}$ and $\mathrm{ART}$ initiation in patients presenting with HIV/TB dual infection with $\mathrm{CD}_{4}$ matched cohort of TB uninfected HIV patients initiated on ART and they found that in dually infected subjects, $\mathrm{CD}_{4}$ count improved from 150 cells $/ \mathrm{mm}^{3}$ to 345 cells $/ \mathrm{mm}^{3}$ ( $p$ $=0.001$ ) and in the control TB uninfected patients, the change was from 159 cells $/ \mathrm{mm}^{3}$ to 317 cells $/ \mathrm{mm}^{3}(p=0.001)$. This study showed that a greater increment in $\mathrm{CD}_{4}$ counts with ATT and ART in dually infected patients suggests that TB additionally influences the reduction of $\mathrm{CD}_{4}$ counts in HIV patients. $^{20}$

TB and HIV infection are wasting diseases that frequently occur together. Weight of the patients was assessed and recorded before and after ATT. On comparison, with a CI of $95 \%$ and $p$ value $<0.001$, mean weight gain seen in patients after completion of ATT was seen to be $8.491 \pm$ $5.436 \mathrm{~kg}$, which is statistically significant. Maximum weight gain was seen in the fifth and sixth decades. In a study done in HIV negative patients it was seen that Indian patients with MDR-TB treated with individualized therapy reported that weight gain after 6 months of therapy was a predictor of successful outcome. ${ }^{21}$ Thus, it is evident that early and complete ATT helps in control of symptoms and improves the overall health status of an already immunocompromised individual. This subsidence of symptoms and monitoring of weight can go a long way in helping clinicians to monitor disease progress and institute appropriate interventions in case of unresponsiveness or failure of treatment as witnessed by worsening of symptoms or ongoing weight loss.

Another interesting finding of our study was that patient showed a significant fall in plasma viral load at the end of completion of ATT, the results of which were statistically significant. One of the possible expla- nations for this could be because of better adherence of ART which gets reinforced when patient develops a symptomatic opportunistic infection. Another big step by the government has been the integration of DOTS and National AIDS Control Programme (NACO) which helps in better co-ordination of the ART and ATT services which could help to improve the adherence to therapy. ${ }^{22}$ Various studies have shown increased HIV replication near site of tubercular granuloma which is dependent on the inflammatory milieu of the site. ${ }^{23,24}$ The successful control of TB infection could help limiting the viral replication, the results of which have been seen in our study. In a systemic review done to find out the effect of treatment of co-infections in HIV positive patients, it was seen that treatment of co-infections results in suppression of HIV plasma viral load. ${ }^{25}$

ATT has been shown to have various adverse effects on the body. In our study we found that only two patients of our study sample (3.7\%) developed adverse reactions to ATT. Various other studies have shown the incidence of hepatoxicity ranging from $6.9 \%-8.7 \%{ }^{26,27}$

\section{CONCLUSION}

TB poses a significant threat to global health still today, causing the second highest mortality rates from an infectious disease worldwide, after HIV/AIDS. In this study, an analysis of 54 patients was done who were diagnosed to have Disseminated TB and HIV co-infection. Maximum cases were in the third decade of age. Radiological findings contributed to the diagnosis in $92.6 \%$ of the cases, $88.89 \%$ had clinical features suggestive of the disease but only $3.4 \%$ had sputum positive for AFB. Lymphatic system was the most commonly involved organ in this series (64.81\%).

Thus, it would be prudent to focus on the clinical findings with support of radiological investigations to diagnose DTB in seropositive cases of HIV rather instead of an advanced battery of investigations and that $\mathrm{CD}_{4+}$ count is a reliable indicator of therapeutic response in such cases.

\section{ACKNOWLEDGEMENT}

None.

\section{CONFLICT OF INTEREST}

The authors declare no conflict of interest.

\section{ABBREVIATIONS}

HIV: Human Immunodeficiency Virus; DTB: Disseminated Tuberculosis; AIDS: Acquired Immune Deficiency Syndrome; $\mathbf{C D}_{4}$ : Cluster of Differentiation 4; ATT: Anti-tubercular Therapy; ART: Anti-retroviral Therapy; CECT: Contrast enhanced computed tomography.

\section{REFERENCES}

1. WHO. Global tuberculosis report. World Health Organization, Geneva. 2016.

2. Maher D, Chaulet P, Spinaci S, et al. HIV infection and Tuberculosis: Guidelines for National Programmes, Geneva, WHO. 1997;45-8.

3. Telzak EE. Tuberculosis and Human immuno deficiency virus infection. Med Clin North Am. 1997;81:345-60.

4. Maheswari DU, Rajakannan D, Durairaj A. HIV and Tuberculosis: Study of 75 cases from Madras. JAPI. 1995;43(12):938.

5. WHO. Definitions and reporting framework for tuberculosis - 2013 revision, World Health Organization, Geneva. 2013;40. WHO/HTM/TB/2013.2

6. Mphothulo N, Pengpid S, Peltzer K. Factors Associated with Tuberculosis Reinfection and Treatment Failure in Taung Sub-District, South Africa. Ethno Med. 2012;6(1):23-30.

7. Kamath R, Sharma V, Pattanshetty S, Hegde MB, Chandrasekaran V. HIV-TB coinfection: Clinico-epidemiological determinants at an antiretroviral therapy center in Southern India. Lung India. 2013;30(4):302

8. Mert A, Arslan F, Kuyucu T, et al. Miliary tuberculosis: Epidemiological and clinical analysis of large-case series from moderate to low tuberculosis endemic Country. Medicine. 2017;96(5):e5875. 10.1097/MD.0000000000005875 
9. Thakur R, Sashindran VK. A Study of Clinical Profile of Recurrent Tuberculosis in People Living with HIV/AIDS. J Aids Clin Res. 2018;9(4):764. DOI: 10.4172/21556113.1000764.

10. Gupta PR. Difficulties in managing lymph node tuberculosis. Lung India. 2004;21(5):50-3.

11. Hochedez P, Zeller V, Truffot C, Ansart S, Caumes E, Tubiana R, et al. Lymphnode tuberculosis in patients infected or not with HIV: General characteristics, clinical presentation, microbiological diagnosis and treatment. Pathologie-biologie. 2003;51(8-9):496-502.

12. Nachiappan AC, Rahbar K, Shi X, Guy ES, Mortani BEJ, Shroff GS, et al. Pulmonary Tuberculosis: Role of Radiology in Diagnosis and Management. Radio Graphics. 2017;37(1):52-72.

13. Noronha AL, Bafica A, Nogueira L, Barral A, Barral-Netto M. Lung granulomas from Mycobacterium tuberculosis/HIV-1 co-infected patients display decreased in situ TNF production. Pathol Res Pract. 2008;204(3):155-61

14. Fontanilla JM, Barnes A, Reyn CFV. Current diagnosis and management of peripheral tuberculous lymphadenitis. Clin Infect Dis. 2011;53(6):555-62.

15. Kim DW, Jung SJ, Ha TK, Park HK. Individual and combined diagnostic accuracy of ultrasound diagnosis, ultrasound guided fine-needle aspiration and polymerase chain reaction in identifying tuberculous lymph nodes in the neck. UItrasound Med Biol. 2013;39(12):2308-14

16. Ellis PK, Martin WJ, Dodd PJ. CD4 count and tuberculosis risk in HIV-positive adults not on ART: A systematic review and meta-analysis. Peer J. 2017:5:e4165 Published 2017 Dec 14. doi:10.7717/peerj.4165

17. Gupta RK, Lawn SD, Bekker LG, Caldwell J, Kaplan R, Wood R. Impact of human immunodeficiency virus and CD4 count on tuberculosis diagnosis: Analysis of city-wide data from Cape Town, South Africa. Int J Tuberc Lung Dis. 2013;17(8):1014-22.

18. Brenda EJ, Summer MM, Young DA, PaulT D, Kramer F, Barnes PF. Relationship of the manifestations of tuberculosis to $C D_{4}$ cell counts in patients with human immunodeficiency virus infection. Am Rev Respir Dis. 1993;148(5):1292-7.

19. Skogmar $S$, Schön $T$, Balcha TT, et al. CD cell levels during treatment for tuberculosis (TB) in Ethiopian adults and clinical markers associated with $C_{4}$ lymphocytopenia. PLoS One. 2013;8(12):e83270. Published 2013 Dec 16. doi: 10.1371/journal.pone.0083270.

20. Wanchu A, Kuttiatt VS, Sharma A, Singh S, Varma S. $C D_{4}$ cell count recovery in HIV/TB co-infected patients versus TB uninfected HIV patients. Indian J Pathol Microbiol. 2010;53(4):745-9.

21. Dhingra VK, Rajpal S, Mittal A, Hanif M. Outcome of multi-drug resistant tuberculosis cases treated by individualized regimens at a tertiary level clinic. Indian J Tuberc. 2008;55(1):15-21.

22. NACO C. National framework for joint HIV/TB collaborative activities. New Delhi, National AIDS Control Organization and Central TB Division, Ministry of Health and Family Welfare, Government of India. 2009.

23. Hoshino Y, Hoshino S, Gold JA, Raju B, Prabhakar S, Pine R, et al. Mechanisms of Polymorphonuclear neutrophil mediated induction of HIV-1 replication in Macrophages during pulmonary tuberculosis. Journal of Infectious Diseases. 2007; 195(9):1303-10.

24. Hoshino $Y$, Nakata $K$, Hoshino $S$, Honda $Y$, Doris BT, Shioda $T$, et al. Maximal HIV1 replication in alveolar macrophages during tuberculosis requires both lymphocyte contact and cytokines. The Journal of Experimental Medicine. 2002:195(4):495-505

25. Modjarrad K, Vermund SH. Effect of treating co-infections on HIV-1 viral load: A systematic review. The Lancet Infectious Diseases. 2010;10(7):455-63.

26. Jeong I, Park JS, Cho YJ, et al. Drug-induced hepatotoxicity of anti-tuberculosis drugs and their serum levels. J Korean Med Sci. 2015;30(2):167-72

27. Abbara A, Chitty S, Roe JK, et al. Drug-induced liver injury from anti-tuberculous treatment: A retrospective study from a large TB centre in the UK. BMC Infect Dis. 2017;17(1):231. Published 2017 Mar 24. doi:10.1186/s12879-017-2330-z

Cite this article : Thakur R, lqbal MS, Farah S. Clinical Profile of Patients with Disseminated Tuberculosis (DTB) in Human Immune Deficiency Virus (HIV)

Infection. Int J Med Public Health. 2019;9(4):131-6. 